\title{
O AGRONEGÓCIO DE GRÃOS E AS INTENCIONALIDADES CAPITALISTAS E CAMPONESAS NOS CERRADOS DE ENTRE RIBEIROS - PARACATU/MG
}

\author{
Rosselvelt José Santos \\ Professor Doutor do Programa de Pós-Graduação em Geografia - UFU \\ rosselvelt.ufu@gmail.com \\ Pedro Machado de Oliveira \\ Doutorando em Geografia pelo Programa de Pós-Graduação em Geografia - UFU \\ quilombodosbagres@yahoo.com.br
}

\begin{abstract}
RESUMO
O texto tem como objetivo analisar os múltiplos usos dos Cerrados no Entre Ribeiros, no município de Paracatu-MG pelos sujeitos sociais encontrados no lugar: os camponeses e os colonos. No lugar, a pecuária praticada extensivamente até a década de 1980 cedeu espaço aos grãos, metamorfoseando-se novamente na virada do milênio com a apropriação parcial de seus solos para o cultivo da cana. Contudo, a lógica da reprodução do capital, hegemônica, mas não absoluta, coexiste com outras lógicas sociais vinculadas aos modos de vida dos assentados do Projeto de Assentamento Santa Rosa. A reprodução dos capitais investidos no agronegócio de grãos e as intencionalidades camponesas são analisadas a partir da instalação de novas estruturas, como os laticínios, as cooperativas e os bancos, inserindo no lugar, novos nexos com o mundo.
\end{abstract}

Palavras-chave: Assentados. Camponeses. Colonos. Capitalistas.

\section{GRAIN AGRIBUSINESS AND THE CAPITALIST AND PEASANT INTENTIONALITIES IN THE CERRADO VEGETATIONS OF ENTRE RIBEIROS - PARACATU/MG}

\begin{abstract}
This study aims to analyze the multiple uses of the cerrado vegetations by peasants and settlers, social subjects found in Entre Ribeiros, a rural region of the city of Paracatu, State of Minas Gerais, Brazil. There, livestock were extensively kept until the 1980s, when the grains began to be grown. Then, over the year 2000, another change was made, since part of the soil had been appropriated to cultivate sugarcane. However, the logic about the reproduction of capital, this is, hegemonic, but not absolute, coexists with other social logics related to the lifestyle of members of the rural settlement project Santa Rosa. The reproduction of the capital invested in grain agribusiness and the peasants' intentionalities are analyzed from the installation of new structures, as dairy products, cooperatives and banks, inserting in the region new relations with the world.
\end{abstract}

Keywords: Rural settlement. Peasants. Settlers. C'apitalist.

\section{INTRODUÇÃO}

Neste texto analisamos os múltiplos usos dos Cerrados do Entre Ribeiros, no município de ParacatuMG, assim como os diversos territórios emergidos a partir de processos de desterritorialização e reterritorialização nas áreas cultiváveis do município. A década de 1980 marca o início de uma transformação fomentada por uma nova orientação produtiva que inclui o lugar Entre Ribeiros no processo de reprodução ampliada do capital. A atividade pecuária, praticada de forma extensiva até a década de 1970, cedeu espaço para o cultivo de grãos na década seguinte, sendo que na virada do milênio estes espaços se metamorfoseiam novamente, tendo parte de seus solos ajeitados para o cultivo da cana-de-açúcar.

$\begin{array}{llllll}\text { Caminhos de Geografia } & \text { Uberlândia - MG } & \text { v. 19, n. } 67 & \text { Set/2018 } & \text { p. 1-15 } & \text { Página } 1\end{array}$


O Entre Ribeiros pode ser compreendido como um território reocupado e revalorizado pelo capital, a partir do agronegócio, contudo, ao mesmo tempo, configura-se como espaço que reúne diferentes temporalidades e lógicas sociais. Trata-se de um espaço que abarca várias territorialidades e tensões derivadas de diferentes interesses. Assim, as altercas envolvem lutas pela terra, contendas das quais originou o Assentamento Santa Rosa, conforme mapa na figura 1.

Neste contexto, o Entre Ribeiros se apresenta como um espaço tenso, dinâmico, contraditório e repleto de ações objetivadas na definição de territórios. Desde suas primeiras reocupações, baseadas na expulsão indígena, na formação de fazendas de gado criado solto e no desmatamento para receber os incentivos do Estado, os usos dos recursos naturais sempre estiveram em disputa.

Figura 1: Mapa do município de Paracatu-MG - No destaque o assentamento Santa Rosa e o Entre Ribeiros.

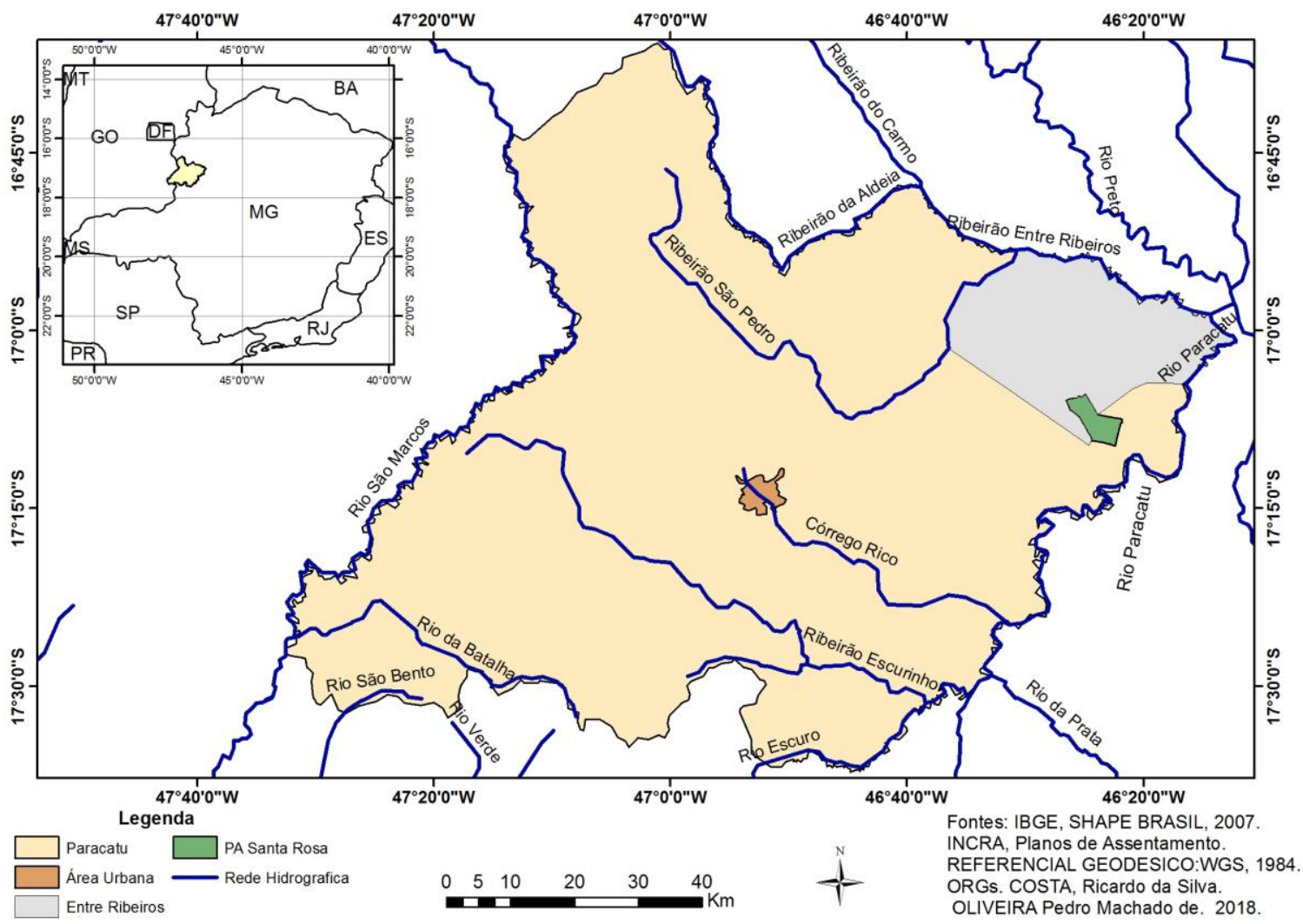

Org.: COSTA, R.S.; OLIVEIRA. P. M. (2018).

$\mathrm{Na}$ atualidade, naquele espaço, a presença de classes sociais diferentes, propicia lógicas sociais em oposição a esses mesmos usos. Na área de estudo, cartografada a partir do mapa do município de Paracatu-MG, com destaque para o Projeto de Assentamento Santa Rosa, próximo ao ribeirão Entre Ribeiros, que dá nome ao lugar, têm-se também áreas de colonização assumidas legitimamente e legalmente pelos colonos trazidos do Sul do país, na década de 1980, pelo projeto JICA (Japan International Cooperation Agency). Nestas fazendas o uso de ciência e tecnologia faz surgir uma agricultura de "precisão" que proporciona a linearização do tempo, garantindo várias safras durante o ano. Por outro lado, na mesma localidade, as terras que foram retomadas por um processo de luta, estão sob o domínio dos camponeses. Nelas vivem pessoas, cujo ritmo das atividades ocorrem imbricadas aos ciclos naturais do Cerrado. A partir do assentamento rural, os camponeses constituíram a comunidade, suscitaram estratégias de estilo múltiplo, derivadas de um conjunto de práticas sociais e culturais que aos poucos foram alterando as paisagens. 
Há ainda uma grande disputa por água, movida principalmente pela pressão do agronegócio. No Entre Ribeiros, as grandes lavouras de grãos são irrigadas. Os colonos usam sementes selecionadas, adubos e fertilizantes químicos, várias máquinas e equipamentos modernos, além de tecnologias da informação que orientam os produtores no emprego e na otimização dos usos dos pivôs centrais.

A reocupação e revalorização dos Cerrados do Entre Ribeiros vai permitir a construção de territórios abalizados para os distintos sujeitos que chegaram ao lugar. $\mathrm{O}$ entendimento sobre o território tem como referência as afirmações de Oliveira 1996.

\begin{abstract}
É, pois um produto concreto da luta de classes travada pela sociedade no processo de produção e reprodução de sua existência. São, pois, relações sociais de produção e o processo contínuo e contraditório de desenvolvimento das forças produtivas que dão configuração histórica específica ao território. O território não é um prius ou um a priori mas a contínua luta das classes sociais pela socialização igualmente contínua da natureza é, pois, simultaneamente, construção, destruição, manutenção e transformação. É, em síntese, a unidade dialética, portanto contraditória, da espacialidade que a sociedade tem e desenvolve de forma desigual, simultânea e combinada, no interior do processo de valorização, produção e reprodução. (OLIVEIRA, 1996, p. 12).
\end{abstract}

Entre Ribeiros é, portanto, um pedaço do Cerrado mineiro onde os diferentes sujeitos sociais participam de uma unidade dialética resultante do processo de produção e reprodução social contemporâneo. De um lado estão os 87 colonos dispondo de 30.000 hectares de terras planas e irrigadas em lotes com áreas entre 185 e 400 hectares, que produzem grãos e cana seguindo a lógica da reprodução ampliada do capital. De outro, encontram-se 65 famílias assentadas usufruindo de 2.400 hectares de terras, com lotes de 36,7 hectares cada, produzindo leite e frutas - e até mesmo se assalariando temporariamente - buscando basicamente o sustento da família, na qual estabelecem seus projetos de vida.

Os critérios políticos de acesso aos recursos financeiros aprofundam as diferenças entre os dois grupos. Claramente mais acessíveis no grupo de colonos, permitem a eles a aquisição de diversos bens/meios de produção, além da apropriação robusta dos recursos "terra e água". Essa situação tornou o lugar Entre Ribeiros um espaço favorável para refletirmos sobre as experiências das pessoas vindas de vários lugares e que de algum modo, a partir das suas práticas sociais fixaram-se no espaço, estabelecendo no cotidiano, práticas sociais que foram transmitindo e reinventando suas identidades, pertenças e representações.

Desse modo, o estudo do lugar considerando suas diferentes temporalidades e sujeitos sociais, parte da compreensão de que até determinado período, década de 1970, a produção do espaço no Entre Ribeiros era concebida a partir da combinação "pecuária extensiva/grande propriedade"; e que na virada deste milênio, manifesta-se de forma distinta. Com a reinserção de diferentes sujeitos no lugar - assentados e colonos -, a produção agrícola em seus territórios se diferencia e entra em contradição, podendo ser analisada a partir da oposição entre os binômios capital/trabalho e/ou grande lavoura/pequena produção leiteira.

No estudo do lugar, os vínculos territoriais, em especial aqueles brotados dos tirocínios sociais conectados aos modos de vida, relacionados à defesa do território são discutidos como um processo em construção, como "[...] uma relação com as externalidades, com os vários âmbitos da integração socioespacial, que nos dirá sobre a sujeição a tais, que implique em desterritorialização e reterritorialização dominantes ou, construção de territorialidades autocentradas" (HEIDRICH, 2004, p.63).

$\mathrm{Na}$ área de estudo, além do fato de serem beneficiários das políticas públicas do governo federal, observamos também que, tanto os assentados quanto os colonos, já haviam vivenciado processos de desterritorialização. Os primeiros perderam o vínculo com a terra no contexto da modernização da agricultura iniciada no lugar no início dos anos 1980; já no caso dos segundos, a pressão populacional e por terras no Sul no país motivaram a migração destes rumo aos Cerrados do Brasil Central. Seja na forma de Projetos de Colonização, seja na forma de Projetos de Assentamentos, as terras planas do Entre Ribeiros possibilitaram processos de reterritorialização para ambos.

\title{
PROCESSOS “MODERNOS” DE REOCUPAÇÃO DO CERRADO
}

A reocupação dos Cerrados, promovida pelo governo militar como política de integração, reocupação, revalorização e modernização do território na década de 1970 vai se manifestar no município de

$\begin{array}{llllll}\text { Caminhos de Geografia } & \text { Uberlândia - MG } & \text { v. 19, n. } 67 & \text { Set/2018 } & \text { p. 1-15 } & \text { Página } 3\end{array}$


Paracatu-MG especialmente no decorrer dos anos de 1980 com dois projetos do Programa de Cooperação Nipo-Brasileiro para o Desenvolvimento dos Cerrados (PRODECER), a saber: o Projeto de Colonização Mundo Novo e o Projeto de Colonização Paracatu Entre Ribeiros. A pesquisa, no entanto, envolve apenas este último projeto. Os novos usos do Cerrado no lugar "Entre Ribeiros" serão redefinidos no contexto da modernização da agricultura, a qual foi planejada, estimulada pelo Estado e financiada pelo capital internacional.

A integração nacional foi uma bandeira da ditadura militar. Levar o desenvolvimento para os sertões do país ocupou centralidade nos discursos oficiais. Nos Cerrados, os estrategistas militares evocavam as intervenções como medidas que promoveriam o seu melhor aproveitamento econômico. O receituário consistia em nutrir o processo de modernização dos Cerrados a partir da técnica, ciência e pesados investimentos de capitais internacionais.

$\mathrm{Na}$ visão dos técnicos japoneses que produziram o relatório JICA em 1979, as áreas de Cerrados eram consideradas como um imenso espaço inexplorado, vazio de população, de capital, de produção e de atividade econômica, conforme indica Pessôa (1988). Portanto, áreas onde se desenvolvia uma pecuária e uma agricultura de "baixa" produção e produtividade, revelando uma situação de atraso econômico e de pobreza na qual viviam as pessoas. Representavam áreas que, na visão de Golbery do Couto e Silva, citado por Santos (2008), o Estado definia como problemáticas, pois no campo econômico apresentavam formas ultrapassadas, tais como o pastoreio extensivo e rude, práticas similares às das regiões Nordeste e Centro-Oeste.

Estes espaços que agora se metamorfoseiam pela ação combinada do Estado e do capital transnacional, apareciam no cenário nacional desde o ciclo da mineração, como importantes áreas criadoras de gado no Brasil. Silva (2012, p, 53) indica que depois da Comarca do Rio das Mortes, era Paracatu o maior fornecedor de gado da capitania, gado que se levava, cruzando toda a extensão do território dela, até o Rio de Janeiro.

Para Lourenço (2005), a exaustão das "minas" de ouro não a significou decadência econômica de Paracatu, visto que a atividade pecuária, introduzida antes mesmo da mineração, fora capaz de absorver grandes contingentes da mão-de-obra mineira e permitir a continuidade da ocupação das extensas áreas de Campos e Cerrados da Comarca.

\begin{abstract}
[...] o esgotamento das lavras e das aluviões auríferas, a partir de 1750, causou decréscimo populacional em algumas vilas da região central de Minas, principalmente naquelas cujas atividades de comércio eram alimentadas exclusivamente pelo ouro das lavras. No entanto, isso não significou a decadência da economia mineira. Enquanto a atividade mineradora perdia força e as zonas auríferas se exauriam, outras regiões como a Comarca de Paracatu, do Serro Frio e principalmente a do Rio das Mortes, viram prosperar uma importante economia agropastoril e manufatura. (LOURENÇO, 2005, p. 102-103).
\end{abstract}

Para Silva (2012) a dinâmica política e econômica do arraial se manteve, e mesmo com a escassez do ouro não perdeu sua importância como território, graças à habilidade de adaptar os antigos mineiros à agricultura e transferir o uso da mão-de-obra escrava ociosa da mineração para os campos agrícolas.

Tudo isto vem reforçar o que escreve Santos (2008), pois para o autor, não se tratava de ocupação, mas sim de reocupação, pois nestes espaços havia homens, mulheres, produção, um modo de vida, cultura, práticas sociais e conhecimentos do meio físico no qual viviam, tratava-se, no entanto, de processos de "reocupação, revalorização e redefinição nos usos e apropriações dos recursos dos Cerrados".

Este era o quadro a ser negado no desenho geopolítico dos militares. Justificava-se por este caminho, de se fazer tábua rasa dos modos de vida existentes, as ações truculentas derivadas de uma política modernizante para os sertões do Brasil. Afinal de contas, mesmo sendo postas como "improdutivas", "vazias" e "problemáticas" tinham como atributos o fato de estarem relativamente próximas dos grandes centros consumidores do Centro-Sul do país; dos portos; de terem relevo plano nas chapadas e clima tropical com regime de chuvas concentradas nos meses de verão que se traduz em abundância de água.

Por esta lógica, considerando os adjetivos atribuídos pelo Estado ditatorial aos Cerrados, logo estes se tornariam lugares impróprios para receber investimentos. Nota-se que entrou em cena a estratégia de primeiro desqualificar para depois entregar nossos recursos aos interesses estrangeiros. Assim, contraditoriamente, estes adjetivos citados, foram utilizados como justificativas geopolíticas e

$\begin{array}{llllll}\text { Caminhos de Geografia } & \text { Uberlândia - MG } & \text { v. 19, n. } 67 & \text { Set/2018 } & \text { p. 1-15 } & \text { Página } 4\end{array}$


econômicas para integrar e modernizar o território, e permitir uma ocupação japonesa nos Cerrados do Brasil, assim como colocam San Martin e Pelegrini (1984). Os Cerrados dos sertões eram áreas cujos recursos estavam, por tempos, preservados pelos habitantes/moradores do lugar. Neste contexto, para o Estado oligárquico, que na sua versão ditatorial, precisava apresentar-se como moderno e modernizante, em seu projeto governamental, o Cerrado comparecia na forma de "estoques" de solos, água, dentre outros recursos. Nos projetos desenvolvimentistas tratava-se de áreas prontas para serem acionados/incorporadas a qualquer momento ao processo produtivo, no sentido de contribuir com o desenvolvimento econômico do país.

$\mathrm{Na}$ reocupação, tais adjetivos foram capturados e otimizados, sendo que a natureza do Cerrado logo se transformou em solução na medida em que o bioma foi transformado em celeiro agrícola do mundo. O capital, em sua busca incessante pela reprodução ampliada, procura afastar-se das áreas pouco atrativas; procura se instalar nos melhores lugares, onde as condições são ideais para o seu prolongamento, isto é, onde segurança e rentabilidade estão associadas.

Para o governo militar tornar o Cerrado altamente produtivo era a "salvação da lavoura". Justificavase o desbravamento do Cerrado como uma forma de equilibrar a balança comercial. A produção de exportáveis, tendo como carro chefe a soja, possibilitaria a entrada de dólares, bilhões deles ajudariam a modernizar o país.

Como estratégia para a promoção do chamado desenvolvimento econômico, o governo federal, na década de 1970 lançou as bases para o desenvolvimento e melhor aproveitamento das áreas de Cerrado. Em 1975 lança o Programa de Desenvolvimento dos Cerrados (POLOCENTRO) que começa a ser desmontado ainda em 1979 para dar lugar ao PRODECER neste mesmo ano. A meta do POLOCENTRO era, além da conquista do Cerrado, a produção de grãos, incentivando, assim, a expansão da lavoura modificando, portanto, a utilização da terra no Cerrado, que até aquele momento se configurava como área predominante de pecuária (PESSÔA, 1988).

O Programa de Cooperação Nipo-Brasileira para o Desenvolvimento dos Cerrados (PRODECER), Projeto JICA, ou Projeto Cerrado como foi difundido na região, em sua fase inicial, escolheu três áreas do Estado de Minas Gerais como projeto piloto, nos municípios de Coromandel, Iraí de Minas e Paracatu. Paralelamente às políticas federais, ocorriam as políticas estaduais para o desenvolvimento do Cerrado mineiro: Programa de Crédito Integrado e Incorporação dos Cerrados (PCl) em 1972 e o Programa de Assentamento Dirigido do Alto Paranaíba (PADAP) em 1973.

Para a região Noroeste de Minas Gerais, onde está o município de Paracatu, na mesma época, o governo do Estado implantou o Programa Integrado de Desenvolvimento da Região Noroeste de Minas (PLANOROESTE), cuja finalidade era oferecer a infraestrutura básica no setor de transportes e eletrificação rural, permitindo a colonização de algumas áreas da região e introduzindo cultivos como arroz, café, além do feijão, milho, cana e mandioca já cultivados, conforme Oliveira Mello (2002).

No lugar, Entre Ribeiros, a planura do terreno torna tais áreas ideais para os cultivos que têm mais capacidade de receber mecanização, como a soja, milho e cana. Além da apropriação pelo capital das terras planas, outro recurso de importância relevante que vem sendo capturado e usado é a água. Com boa disponibilidade do recurso, canais de irrigação foram construídos para se promover uma agricultura irrigada de elevada produção e produtividade.

Os 10.315 hectares do Projeto de Colonização Paracatu Entre Ribeiros I (PCPER I) projeto iniciado em 1983 - foram recortados por canais que permitiam circular a água do ribeirão que dá nome ao lugar. Os sistemas de irrigação foram coordenados pela Fundação Rural Mineira (RURALMINAS) conforme Ricci dos Santos (2007). Diante de resultados que superaram expectativas com a possibilidade de obterem três safras anuais, os projetos de colonização no Entre Ribeiros tiveram continuidade. Nos anos de 1986 e 1987 com recursos do PRODECER II, foram implantados os Projetos de Colonização Paracatu Entre Ribeiros II e III, PCPER II e III com uma área total de 16.796 hectares. Estes utilizam água do rio Paracatu, onde a oferta hídrica é maior do que no ribeirão Entre Ribeiros.

Dando continuidade a reocupação dos Cerrados daquele lugar, em 1990 foi iniciado o PCPER IV com área de 3.984 hectares. Ao todo os quatro projetos somam mais de 30.000 hectares. Apenas no Projeto IV os canais de irrigação não foram construídos em decorrência da extinção da entidade financiadora, o Banco Nacional de Crédito Cooperativo (BNCC) em 1992.

Sem dúvida, as características naturais, como relevo plano, clima e disponibilidade de água foram essenciais para a manutenção de práticas governamentais de financiar projetos de modernização da 
agricultura nos cerrados. Assim, é indiscutível a importância das alianças entre Estado e capital e das tecnologias aplicadas nesta chamada modernização.

O processo de reocupação também fixou os colonos que investem dinheiro nas suas lavouras para obterem lucros, visando acumulação do capital. Nesta relação com o agronegócio sofrem pesadas imposições, resultando na necessidade de dilatar as suas safras agrícolas e de aumentar o consumo dos insumos. Nesta lógica social, a apropriação dos recursos hídricos e o incremento de tecnologia propiciam segurança de rentabilidade ao capital já investido.

Para esses sujeitos o mercado exige cada vez mais aceleração do tempo de produção, exercendo um caráter monopolizador direcionado à produção para obtenção de lucro. Nesta lógica das coisas a vida humana vai sendo ocupada por relações "coisais" e o próprio mercado vai exigido maior dedicação daquelas pessoas às lavouras e às coisas atreladas aos processos reprodutivos do capital. Isto é, nas relações com o mercado o homem perde a condição de sujeito dominante, de modo que passa a ser visto como mais um dos elementos que possibilitam a reprodução do capital, assume a condição de sujeito sujeitado. Neste processo, o tempo torna-se uma raridade, dificultando/bloqueando as possibilidades de exercer autonomia frente às novas conquistas, sobretudo as econômicas.

A agricultura associada ao capital e ao Estado revela características distintas daquela tradicionalmente desenvolvida em toda a região Noroeste de Minas onde está o município estudado. Os cultivos tradicionais produzidos em pequena escala nas unidades familiares, cederam espaço para as vultosas monoculturas nas propriedades dos colonos. E assim, com a territorialização do capital, a agricultura tem a sua função alterada; não cabe mais a ela o papel de produzir o sustento do habitante do lugar, mas de garantir a reprodução dos capitais investidos. Na relação com o espaço, com o capital e com o mercado, também o migrante já não é mais o mesmo, foi se metamorfoseando em colono/capitalista/rentista.

Contudo, do ponto de vista social, a modernização imposta, trazida de fora para dentro, não acarretou benefícios e, antes de tudo significou expropriação, expulsão e pauperização para a população local, visto que foram excluídos dos projetos de colonização. Além da marginalização das pessoas do lugar, que se revela como "custos sociais da modernização", os custos são também ambientais.

No lugar estudado, as práticas cotidianas dos produtores agrícolas ligados ao agronegócio propiciaram a alteração radical da paisagem a partir da retirada da cobertura vegetal, drenagem de solos úmidos, implantação da monocultura e da irrigação. Essas práticas socioprodutivas levaram o ribeirão Entre Ribeiros a secar no ano de 2002, de acordo com Ricci dos Santos (2007).

O processo no qual é desenvolvida a agricultura irrigada no Entre Ribeiros não poderia conduzir a resultados distintos deste. Os avanços tecnológicos alcançados pela indústria e aplicados na agricultura em seu processo de modernização, permitiram aos empresários rurais reproduzirem artificialmente as condições de produção agrícola, a fabricar a própria natureza, como indica Silva (1982). Ocorre que nesse processo há a transformação de ambientes ecologicamente estáveis, onde o ciclo da vida dependia das estações chuvosas e secas. No Entre Ribeiros, segundo moradores do lugar, as paisagens combinavam áreas de terras úmidas com áreas de Campos e Cerrados, "um pequeno pantanal no município de Paracatu", declaram os antigos moradores do lugar. Ali, a fabricação da natureza incluiu obras de drenagem (figura 2), construção de canais, correção dos solos e instalação de sistemas de irrigação (figura 3).

Figura 2: Canal de drenagem. Construído para drenar áreas úmidas. 


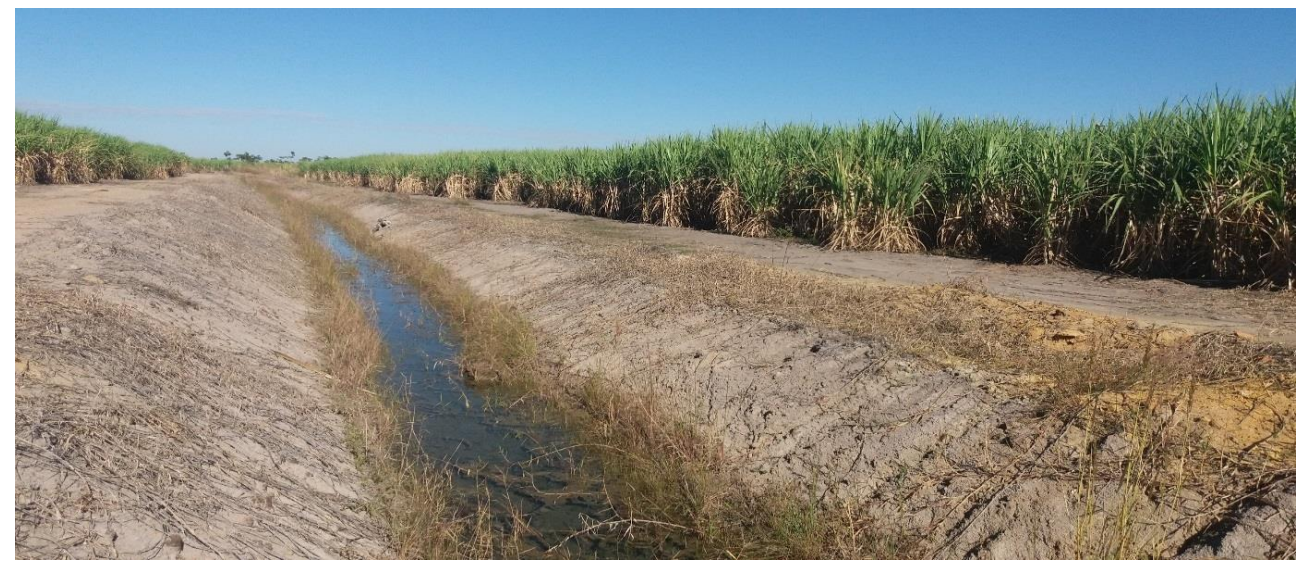

Fonte: OLIVEIRA, P. M. (2017).

Figura 3: Cana irrigada por pivô central em solo drenado.

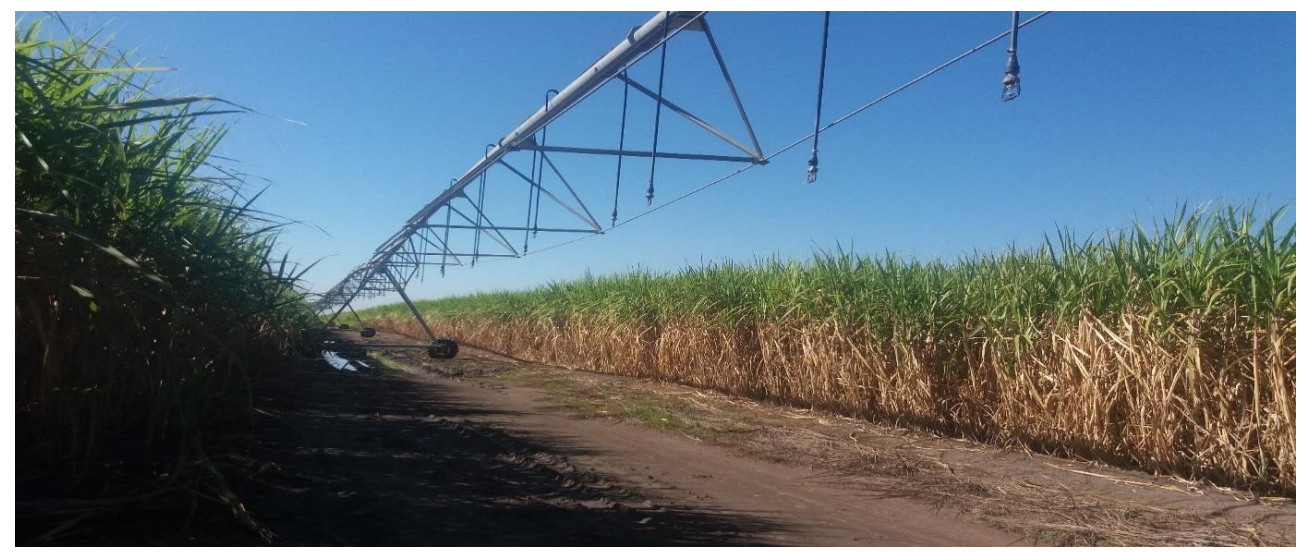

Fonte: OLIVEIRA, P. M. (2017).

A industrialização da agricultura representa o último passo da subordinação da natureza ao capital, quando então se prescinde das condições naturais dadas e passa a produzi-las sempre que se fizerem necessárias. O domínio da técnica e a suposta subordinação da natureza permitiu ao homem desenvolver ações dissonantes do ciclo natural do Cerrado, onde os excessos se fizeram e (ainda) se fazem notar. Enquanto o habitante tradicional do Cerrado promovia o seu sustento obtendo uma safra por estação úmida, a agricultura modernizada do Entre Ribeiros alcança até três safras anuais.

\begin{abstract}
Assim, se faltar chuva, irriga-se; se não houver solos suficientemente férteis, adubase; se ocorrem pragas e doenças, responde-se com defensivos químicos ou biológicos; e se houver ameaças de inundação, estarão previstas formas de drenagem. A produção agropecuária deixa, assim, de ser uma esperança ao sabor das forças da natureza para se converter numa certeza sob o comando do capital (MIRANDA NETO, 1982, p.90).
\end{abstract}

O autor afirma que essa agricultura moderna transforma recursos renováveis como o solo vivo em recursos não renováveis. Assim, cada safra passa a significar um saque à natureza (combustíveis fósseis, solos e água) e não mais o produto de um ciclo natural de produção de matéria orgânica.

Plantadores de cana irrigada orgulham-se em afirmar que chegam a colher 230 toneladas a partir da segunda safra. Falam que no sétimo ano da safra, quando as áreas tradicionais como Alagoas e São Paulo já estão renovando o plantio, colhem no mínimo 140 toneladas por hectare, o que é considerado algo excepcional, considerando as médias nacionais em torno de 80 toneladas/hectare. Não restam dúvidas quanto ao êxito alcançado no quesito produtividade tanto desta quanto dos demais cultivos irrigados. O feijão, por exemplo, alcança a marca de 55 sacas por hectare, enquanto a soja chega a 65 sacas e nesse ritmo os demais cultivos como o milho, abóbora, além da alfafa e do tifton dos quais se fazem o feno.

Os números citados servem para ilustrar o quão vultoso é o "saque" dos recursos naturais e o quão rentável é o agronegócio no lugar. Percebe-se, no entanto, que os conhecimentos tecnológicos

\begin{tabular}{llllll}
\hline Caminhos de Geografia & Uberlândia - MG & v. 19, n. 67 & Set/2018 & p. 1-15 & Página 7
\end{tabular}


desenvolvidos e aplicados na agricultura moderna foram canalizados tão somente para o alcance da maior produtividade, não havendo assim a conciliação entre elevada produtividade e preservação dos recursos naturais, bem como da promoção da justiça social. Retomamos as ideias de Miranda Neto (1982, p.95), para o qual o conceito de tecnologia avançada não deveria estar necessariamente vinculado à ideia de ser a mais moderna, nem a mais sofisticada ou a mais rentável em termos de produtividade, mas aquela mais adequada ao meio ambiente.

As imagens obtidas em campo e os dados da produtividade ajudam-nos a compreender a lógica capitalista, na qual se deu esse processo de fabricação da natureza no Entre Ribeiros. No entanto, queremos relativizá-lo e indicar que apresenta limites, assim como é carregado de contradições.

Ali os solos estão tratados; canais (figura 4) e sistemas de irrigação estão montados; maquinários e trabalhadores estão apostos e à disposição, bem como o crédito continua disponível para o agronegócio. Contudo, em julho de 2017, alguns pivôs que utilizam águas de pequenas represas já se encontram desativados.

Neste espaço, o fator água tornou-se determinante para a prática de uma agricultura sem interrupção. No entanto, quando a agricultura moderna esgota as águas superficiais (Figura 5) a ideia é buscá-la no subsolo. A sequência das ações antrópicas, no processo que culminou com a escassez do recurso, inicia-se com os desmatamentos, seguidos pela drenagem e irrigação, e parece se intensificar com a tendência observada em vários municípios do Noroeste do Estado, de cada proprietário ter os seus poços artesianos para continuar a prática da irrigação.

A observação das paisagens criadas pela ação dos envolvidos com o agronegócio revela também contradições: cana irrigada em solos drenados. Como os solos encharcados não permitem o plantio nem mesmo a mecanização, urge drená-los. A prática consiste em construir sulcos pelos quais o excesso de umidade é eliminado. Na mesma área, retira-se a água, planta-se cana e depois se irriga.

Em nome da produção de commodities ou de energia denominada absurdamente como limpa, o que se verifica é um duplo golpe nos recursos hídricos do lugar, pois, se por um lado, solos drenados deixam de funcionar como reservas para alimentar os recursos hídricos, de outro utiliza-se da água do rio para promover a irrigação. Num sistema combinado de drenagem e irrigação o resultado é o estrangulamento dos sistemas hídricos locais, que tem o rio Paracatu como principal representante.

Figura 4: Canal de irrigação. A água do rio Paracatu segue por canais que abastecem os pivôs instalados inclusive nas áreas drenadas.

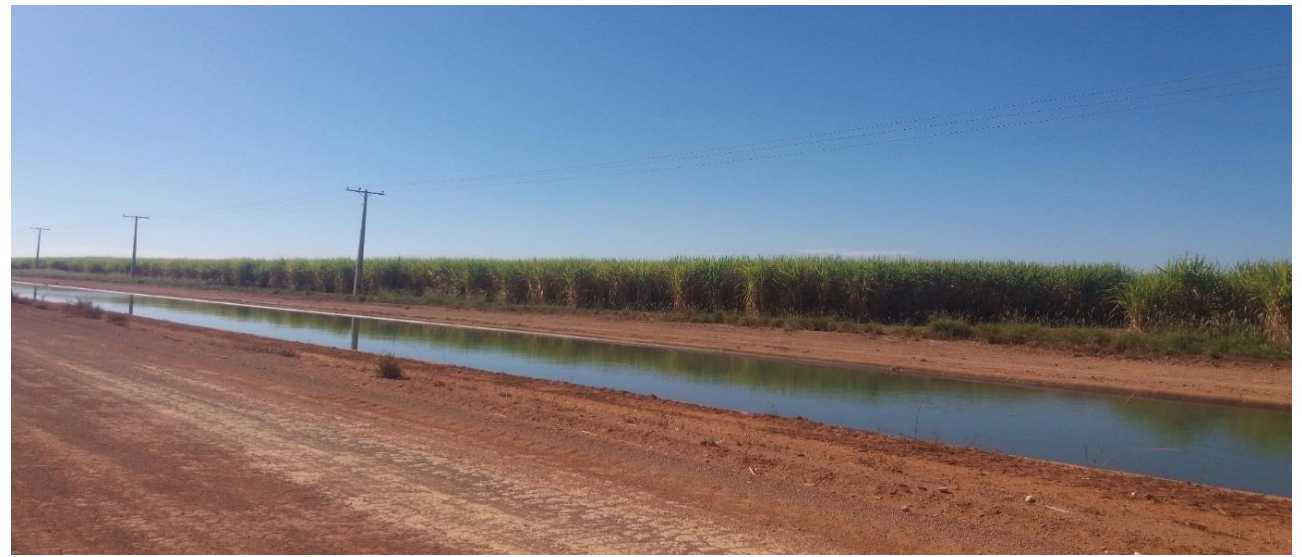

Fonte: OLIVEIRA, P. M. (2017)

Figura 5: Estiagem no Rio Paracatu. Imagem do leito parcialmente seco. Ao fundo, vê-se a balsa utilizada até o ano 2010. 


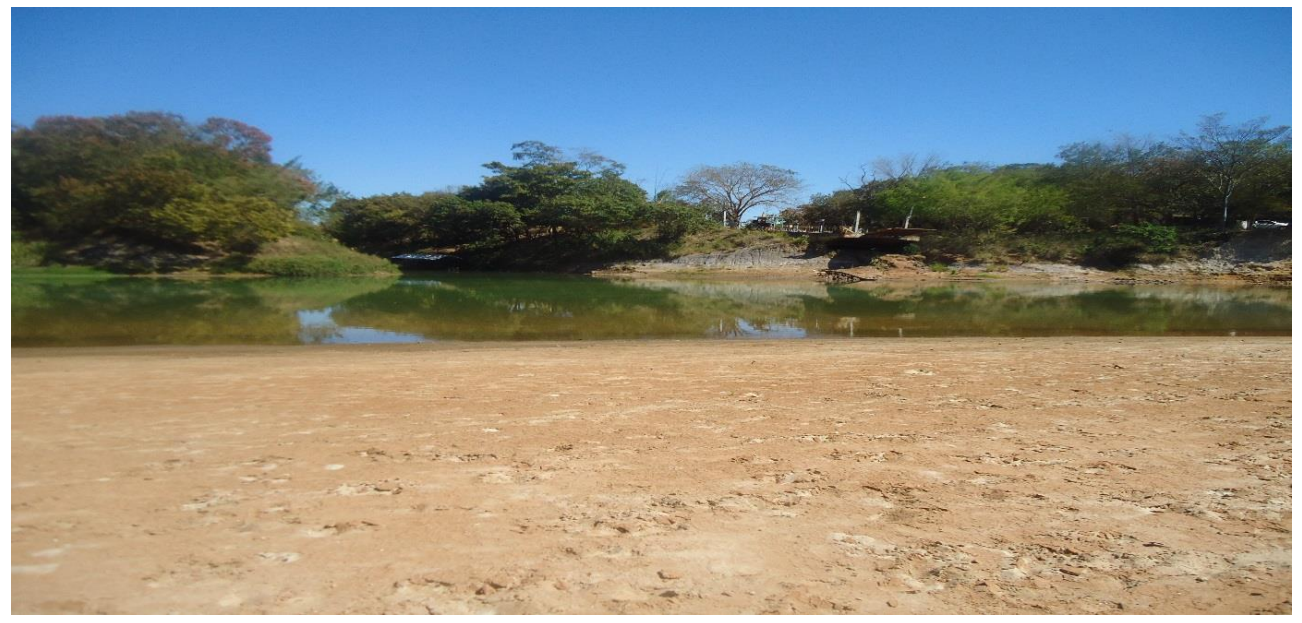

Fonte: OLIVEIRA, P. M. (2017).

A obtenção de um produto que carrega o rótulo de renovável, limpo e que contribui na redução dos níveis de $\mathrm{CO}^{2}$ na atmosfera realiza-se contraditoriamente, com o severo comprometimento de outros recursos naturais. Isto é, se o etanol é tido como combustível limpo, não importa se é produzido a partir de uma monocultura mecanizada e irrigada, que concentra ainda mais a renda nas mãos dos capitalistas e que a um só tempo elimina a biodiversidade local e regional, empobrece os solos, reduz empregos e acentua a escassez dos recursos hídricos.

Souza, (2012, p.79) indica que no processo de reprodução do capital, os valores associados à ótica ambiental podem acabar sendo invertidos. Combinando em uma só atividade a reprodução do capital e o lobby da produção de energia renovável, os fins acabam justificando os meios. Para a autora, "até a própria noção de preservação do meio ambiente, imposta antes como barreira ao desenvolvimento do capitalismo, foi invertida em sua lógica, sendo atualmente assimilada como atributo de valorização ao etanol por conta de seu caráter renovável".

Afora a questão ambiental, outras questões estão relacionadas a este processo de reprodução do agronegócio que se pratica na área de estudo. No lugar acontece a concentração fundiária, expropriação, proletarização camponesa, êxodo rural, consequência da desterritorialização, urbanização acelerada e desordenada a partir da década de 1970 e junto com ela os problemas urbanos. Os problemas são enormes e fazem parte de um pacote de consequências que podem ser atribuídos ao modelo de desenvolvimento que se promoveu no campo brasileiro. Configuram-se como modos operantes do agronegócio que domina as paisagens rurais do território nacional. Para Silva (1982) uma modernização dolorosa, processo que para Carvalho (2005) significou apenas a modernização parcial do latifúndio, pois não alcançou positivamente os pobres do campo; em verdade, sacrificou-os, convertendo "parte dos pobres do campo em novos pobres na cidade", sendo que os primeiros produzem alimentos baratos para alimentar os últimos.

Ocorre que nem sempre este novo pobre, na cidade, assimila o modo de vida urbano. Quando retorna ao campo, motivado pelo programa de reforma agrária brasileira terá que ser reincluído, submetendo-se às imposições do Estado. Esse sujeito não volta ao mundo que vivia. $\mathrm{O}$ seu conhecimento de mundo e as experiências trazidas e que deveria incluí-los precisam ser trabalhadas na perspectiva de viabilizar o seu (re)enraizamento, a reterritorialização.

Como as políticas públicas não acompanham e também não atendem as demandas dos assentados, sentem-se traídos pela forma pela qual se dá o desenvolvimento estrutural da reforma que em muitos casos acaba lançando aqueles sujeitos às margens do sistema dominante. Nesse processo, as lutas dos camponeses pela terra, organizados por movimentos sociais ou de sindicatos rurais, teria que garantir não apenas o lote, mas o retorno a um modo de vida no campo e as condições que lhes possibilitem a criação de territórios camponeses. De tal modo, o processo de exclusão e expropriação dos camponeses, é acompanhado contraditoriamente por um movimento que promete o retorno à terra, mas que não lhe garante permanência.

Assim, a partir da reocupação e da modernização dos Cerrados, os espaços rurais do Entre Ribeiros são tomados por diferentes sujeitos, portadores de diferentes lógicas e temporalidades sociais. Enquanto partes das terras foram apropriadas pelo grande capital, outras foram apropriadas pelos 
trabalhadores rurais, a partir do Assentamento Santa Rosa. Surgem daí distintos territórios que se opõem de acordo com a lógica da reprodução do capital e de modos de vida camponeses.

\section{TERRITÓRIOS DE OPOSIÇÃO}

Compreender o "processo" territorial a partir desses dois sujeitos sociais, o capitalista e o camponês assentado, no Entre Ribeiros, tem várias motivações. A principal delas é discutir sobre a relação existente entre a dificuldade da inclusão social no espaço tomado pela lógica capitalista e a construção de territórios de oposição. Assim, trata-se de reconhecer certa tensão social em um lugar onde as territorialidades surgem em torno daquilo que se poderia reconhecer por uma convivência/tolerância entre diferentes. Expomos os estranhamentos porque não tratamos especificamente da sua conflitualidade, mas da consideração de sua expressão em condição de justaposição no território.

Necessário se fez recorremos aos conceitos de "território", na sua pluralidade, ainda que de modo restrito. Desde a abordagem adotada por Raffestin, na qual o conceito está vinculado às relações de poder, à abordagem de Haesbaert (entre outros), em que o conceito envolve, além das dimensões econômica e política, a dimensão cultural, que valoriza a ação dos elementos humanos na constituição dos mesmos. Pois vimos no Entre Ribeiros o exercício do poder político da União, ao implantar tanto os projetos de colonização quanto o assentamento Santa Rosa; vimos o território sendo apropriado economicamente, já que ali se exploram os recursos do lugar - terra e água; vimos por último, territórios construídos a partir da ação humana, nas relações estabelecidas entre os assentados, que acabam por transformar o território em lugar.

Para Raffestin (1993), os territórios são construídos a partir da ação dos chamados atores sociais a partir das relações de poder: "São estes atores que produzem o território, partindo da realidade inicial dada, que é o espaço. O território é uma construção a partir do espaço. O espaço, nesse caso é, em primeiro lugar, um dado que antecede à intervenção humana. Há, portanto, um "processo" que demarca a partir das relações sociais o surgimento do território. A elaboração do território vai sendo processada a partir da ação, do trabalho destes atores; é visto como uma construção.

Nesta perspectiva, segundo Raffestin (1993), "o território é um espaço onde se projetou um trabalho. No Entre Ribeiros, o trabalho projetado pelos assentados e colonos, materializa-se no espaço, criando várias e distintas paisagens. A observação da paisagem permitiu pensar o processo de reocupação na perspectiva de entender o que a paisagem dessas grandes lavouras e dos lotes camponeses abriga: natureza, história e cultura.

Ao desenvolver o conceito priorizando sua abordagem política e relacionando-o com as relações de poder, considera que todas as organizações, passando da família ao Estado, pelos partidos, pelas igrejas e as empresas, são atores sintagmáticos. "O Estado é um ator sintagmático por excelência quando empreende uma reforma agrária, organiza o território, constrói uma rede rodoviária [...]" (RAFFESTIN, 1993, p.40). A ação deste ator sintagmático se manifesta no Entre Ribeiros propondo os Planos Nacionais de Desenvolvimento; elaborando os programas para o desenvolvimento dos Cerrados como o POLOCENTRO e o PRODECER; implantando projetos de colonização, promovendo projetos de assentamentos da Reforma Agrária, como o Santa Rosa.

Ao pensarmos nessa problemática geográfica, consideramos aquilo que Saquet (2007) acrescenta em seus estudos que o território pode ser visto como uma construção social, resultado da ação dos grupos humanos ocupando certas porções do espaço. Considera o caráter político que o conceito parece carregar consigo nas suas origens, assim como o caráter econômico que o vê o como fonte de recursos a serem apropriados; mas sobretudo, valoriza o território construído a partir de relações estabelecidas entre os grupos humanos no e a partir do espaço.

No debate sobre os territórios, outro autor considerado é Haesbaert (2004, p.40). Ele afirma que os territórios podem ser compreendidos na instância do político como espaços delimitados a partir de relações de poder; na instância cultural, priorizando a dimensão simbólica do grupo através da identificação do mesmo com o espaço vivido. Assim como na abordagem econômica, no qual o território é percebido como fonte de recursos.

Dado o fato de os territórios serem plurais, envolvendo não apenas questões políticas e econômicas, "mas gente", como expõe Kinn (2010), permite-nos fazer a associação do território em sua abordagem cultural, simbólica, no espaço onde se dá a reprodução da vida dos camponeses assentados. Nesse sentido, o território é pensado não somente a partir da apropriação material, mas

$\begin{array}{llllll}\text { Caminhos de Geografia } & \text { Uberlândia - MG } & \text { v. 19, n. } 67 & \text { Set/2018 } & \text { p. 1-15 } & \text { Página } 10\end{array}$


em razão dos princípios de identificação cultural com o meio no qual se relacionam; os vínculos afetivos que se criam na relação com o território lhes conferem pertencimentos e identidades.

No caso dos assentados, os vínculos com o território e a afetividade serão (re)criados na medida em que as práticas sociais ocorrem, na vida cotidiana, como processo de construção do seu território. Assim, na relação entre as transformações da paisagem e o surgimento de outros sujeitos compreende-se a condição do camponês, o qual vai romper com a homogeneização das grandes lavouras no Cerrado. Suas origens ajudam a revelar a sua tradição camponesa.

No lugar, a análise dos meios de vida sugere o estudo das práticas sociais envolvidas em ações de manter o acesso à terra. Nesse costume, a terra é o limite da expropriação de meios de vida. Quando o camponês recupera a posse da terra, ao se tornar um assentado, não the restará apenas a sua força de trabalho, porque também recupera o meio de produção, do trabalho e da vida. Esse sujeito, juntamente com sua família transforma-se em cultivador de alimentos e é a favor de continuar recriando a luta pela sua existência, desde a sua chegada no Entre Ribeiros.

Sendo assim, como sujeitos de ação, os camponeses do lugar trazem em si vários conjugados de estratégias de existência com as quais encaram as imposições sociais, inventam novas racionalidades. Assim, a ciência dos seus movimentos no Cerrado implica no conhecimento das condições dessa dinâmica de transformações.

Por outro lado, associamos os empreendimentos do agronegócio no Entre Ribeiros, materializado nos campos irrigados, aos territórios do capital. Nestes domínios, os produtores de soja e cana agem buscando a remuneração dos capitais investidos. Na perspectiva de suas ações sobressai a questão econômica, na qual os elementos da natureza são vistos antes de tudo como fonte de recursos a serem apropriados.

Na pluralidade de territórios do Entre Ribeiros, o espaço transformado em "arena do capital", Matos (2011), convive com o espaço transformado em território que emerge da luta pela terra. $O$ assentamento Santa Rosa, criado pelo INCRA no ano de 1999 reúne sujeitos que se recusaram a se tornar proletários, embora até possam enfrentar, temporariamente, esta condição. Neste processo o espaço reocupado faz surgir pela ação dos assentados, territórios transitórios, uma vez que nesse processo de transição, os espaços destinados à monocultura passam também a abrigar a produção de alimentos. Neste processo de ceder espaço aos interesses dominantes tem-se rupturas importantes. Assim, mesmo que a pecuária extensiva tenha sucumbido aos interesses do agronegócio dos grãos, no início da década de 1980 e mais tarde, na virada do milênio, a soja tenha cedido espaço à cana, é preciso considerar que a metamorfose ocorrida não homogeneizou as paisagens e nem as práticas sociais das pessoas.

A metamorfose socioespacial ocorrida não aconteceu em uma única direção. Na medida em que seus solos são parcialmente apropriados pela cana-de-açúcar, tem-se o espaço transformado em território camponês com a conquista do assentamento Santa Rosa. Nesse caso, os "territórios em transição" são também múltiplos, plurais, pois as tensões surgidas e nutridas por diferentes lógicas sociais reúnem, embora separados, interesses do capital e do trabalhador que luta para não ser proletário das grandes lavouras.

A partir dessas heterogeneidades, na implantação da agricultura moderna, a territorialização do capital não se dá de forma homogênea nos espaços dos Cerrados. Contudo, a disponibilidade de políticas públicas voltadas para liberação dos recursos financeiros na forma de créditos subsidiados ao agronegócio é condição fundamental para a territorialização do capital.

Neste contexto, o espaço do Entre Ribeiros mostra-se rico pela diversidade de territórios e de interesses que colocam juntos, mas separados no mesmo espaço, capitalistas e trabalhadores. Territórios estes que são construídos a partir da disputa - consequentemente conflitos - não apenas de espaço enquanto área a ser apropriada pela agricultura de grãos, mas de recursos naturais, principalmente a água, já que Entre Ribeiros constituem-se não somente de projetos de colonização, mas também, de grandes projetos de irrigação.

Diálogos com colonos do Entre Ribeiros permitem perceber a transparente satisfação em anunciar que no município de Paracatu, diga-se Entre Ribeiros e seu entorno, existem os maiores complexos de irrigação da América Latina. Ali estão instalados sistemas de irrigação utilizando pivôs centrais que têm a capacidade de irrigar até 500 hectares cada. As áreas irrigadas não são desprezíveis, bem como o número de pivôs existentes no lugar. 
Exatamente em função dos recursos a serem apropriados, os sujeitos do Entre Ribeiros, camponeses e capitalistas, iniciaram novas metamorfoses e tensões correspondentes a partir do ano 2006, quando "territórios dos grãos" começaram a ser apropriados pela cana. Com isso, além da oposição capital $\mathrm{x}$ trabalho, há tensões territoriais entre capital $x$ capital. $O$ novo elemento desta metamorfose se dá com a instalação da planta industrial da Bioenergia do Vale do Paracatu (BEVAP) no município de João Pinheiro, que se apropria de terras cultiváveis nos municípios de João Pinheiro, Unaí, Brasilândia, inclusive das terras irrigadas do Entre Ribeiros.

Ao ocupar um território já dotado de infraestrutura, como vias de circulação, eletrificação rural, sistemas de irrigação e maquinários, a cana avança a passos largos. Estando isenta de realizar investimentos onerosos, como recuperação de solos degradados por pastagens por onde a cana geralmente avança, já que ali os solos encontram-se incorporados ao pleno processo produtivo; a cana promete uma remuneração que anima os colonos/capitalistas/rentistas. Este avanço contínuo sobre as terras do agronegócio de grãos permitiu que a cultura de cana ocupasse já em 2015, metade da área cultivada no lugar.

Contribuindo para tornar ainda mais monótona e vazia de gentes a paisagem do Entre Ribeiros, sua introdução no território dos grãos trouxe implicações também no território camponês. Vai-se acentuar o embate entre o trabalho no assentamento e o trabalho assalariado e temporário na usina entre os próprios assentados. No início da implantação da usina e dos primeiros plantios de cana, cerca de 3600 funcionários estavam envolvidos nas atividades produtivas, muitos deles, do Assentamento Santa Rosa.

Diante da possibilidade de trabalho externo e da produção integrada de leite, aqueles que vivem do trabalho em seus lotes, acabam não produzindo a diversidade de alimentos que garantem autonomia alimentar da família. Além do leite, a produção de frutas, ainda incipiente, é atividade que vem crescendo entre os assentados. O leite tem sido o produto que permite a existência dos assentados no lugar. A produção é adquirida pela Cooperativa Agropecuária do Vale do Paracatu Ltda (Coopervap) - a mesma cooperativa responsável pela execução do Projeto de Colonização Paracatu Entre Ribeiros I em 1983.

Como tantas outras empresas do setor de laticínios, a Coopervap controla o processo produtivo nas suas duas pontas. De um lado, ao agir como compradora, define o preço do leite; na outra ponta do processo, fornece rações, adubos e sementes para os cooperados. No lugar também atua no ramo dos supermercados, farmácia, produtos veterinários, combustíveis, além de operar como mediadora em negociações de tratores, implementos, terras, gado leiteiro e de corte, por intermédio da sua diretoria comercial.

As conversas presenciadas entre os assentados deixam transparecer como os mesmos veem as ações da cooperativa no lugar e como têm consciência da relação estabelecida com a mesma. Nem sempre amistosas, as relações são marcadas muitas vezes por conflitos de interesses.

Quando do início do relacionamento entre os assentados e a cooperativa, a mesma praticava uma política de "cotas" para a produção de leite. A cota era estabelecida pela quantidade de litros de leite produzidos no período da seca. Ora, sabe-se que no município estudado o período ótimo para a produção de leite é no tempo das águas, que geralmente ocorre de novembro a abril. Assim, estabelecer cotas no período da seca tem implicações tanto para a empresa quanto para o produtor. Para a empresa implica acesso ao produto sem os chamados picos de produção verificados na estação chuvosa, seguidos de momentos de declínio da oferta durante a estiagem. Para o produtor a fantasiosa melhor valorização do seu produto durante as águas. Nesse processo há a linearização do tempo e da produção do assentado. Seu ritmo de vida não está mais associado aos ciclos naturais do Cerrado aos quais certamente estavam habituados, mas ditado pela necessidade cotidiana de produzir leite na perspectiva de atender às imposições associadas à política de cota da cooperativa.

Todavia, qualquer quantidade de leite produzido acima do valor da cota no período das águas era considerada "excesso". Os conflitos se dão nesse momento. A situação relatada por um dos produtores de leite no assentamento nos indica a seguinte ordem dos fatos: para o leite produzido dentro da cota, cada litro era remunerado à base de $R \$ 0,80$ centavos (oitenta centavos), porém para cada de litro produzido de excesso era remunerado por apenas $R \$ 0,07$ centavos (sete centavos).

A situação provocou descontentamento entre estes pequenos produtores e em reunião com diretores da cooperativa os mesmos afirmaram que nesta relação contratual estava sendo lesados. Conta o entrevistado que um dos assentados, mostrando ao mesmo tempo seu descontentamento e ironia, ao 
pronunciar o nome da coopervap, acabou entonando a voz na sílaba final (cooperVAP), gesticulando ainda com a mão sinalizando que o seu produto lhe estava sendo indevidamente apropriado.

A consciência que tem o camponês assentado da sua relação subordinada com o mercado o fez denunciar a prática da cooperativa. Para todos os efeitos, não se sabe se decorrente apenas dessa situação conflituosa presenciada no assentamento, ou se esta era também a causa dos demais cooperados, a política de cotas e excesso foi extinta pela cooperativa. No entanto, o evento ficou marcado entre aqueles produtores e continua servindo para evidenciar as práticas cotidianas da cooperativa/empresa enquanto compradora de leite e fornecedora de bens de consumo para os mesmos.

Oliveira (2006), denomina este processo de "monopolização do território pelo capital", processo este no qual não há a necessidade de o capital "territorializar-se" no campo como no caso da cana, nem há a necessidade de varrer tais homens do campo, mas um processo que se caracteriza por apropriar-se, ao mesmo tempo, da renda da terra e do trabalho camponês ao adquirir sua produção.

Em relação ao processo de reprodução do capital, Marcos (2008) observa que as empresas

\begin{abstract}
[...] instalam-se em áreas estratégicas e monopolizam o território, ao determinarem o que ali será produzido, estabelecendo acordos com os pequenos camponeses ou capitalistas que passam a produzir e entregar seus produtos pare serem processados por elas, de acordo com os padrões de qualidade definidos no momento da contratação. Agem sujeitando a renda da terra ao capital e, ao possuírem seus tentáculos em diferentes setores produtivos, o fazem seja através da venda de sementes e insumos (capital comercial), seja através da compra dos produtos para serem processados (capital industrial) seja ainda, em alguns casos, adiantando parte dos recursos necessários para serem investidos no processo produtivo (capital financeiro). (MARCOS, 2008, p. 195).
\end{abstract}

Observamos, no entanto, que no espaço do Entre Ribeiros, as ações relacionadas ao desenvolvimento do capitalismo no campo e à apropriação capitalista dos recursos locais se deram e ainda se dão de forma excludente. Num primeiro momento, quando predominava a pecuária extensiva, era os donos dos bois quem excluía o homem do acesso à terra; em um segundo momento de reocupação dos Cerrados, o homem do lugar novamente foi preterido, pois colonos vindos do Sul vieram amansar e apropriar-se da terra. Estabeleceram nos Cerrado os gaúchos, paulistas, paranaenses; e, especificamente no caso de Paracatu, os colonos Nipo-brasileiros, a maioria destes vindos do Paraná. Num terceiro momento o camponês do lugar, ainda que assentado e, portanto, proprietário, torna-se excluído pelas relações desiguais que estabelecem com o mercado, relações nas quais assume posição subalterna, quer seja quando vende sua própria força de trabalho para o agronegócio, quer seja quando se torna um produtor integrado de leite.

Logo, se chega ao entendimento de que se o projeto modernizante privilegiou a grande lavoura em detrimento da pecuária, assim como privilegiou o colono em detrimento do camponês do lugar, mesmo assim, este sujeito se encontra aí. A sua busca pela reinserção econômica no lugar vai ocorrer por duas vias que se fundem em apenas uma: a pecuária leiteira desenvolvida por camponeses no assentamento Santa Rosa.

Desta forma, os espaços e paisagens do Entre Ribeiros onde predominam as plantações de soja, milho, feijão e cana, capazes de reproduzir apenas capital; com o assentamento, metamorfoseia-se o lugar de produção da vida e de trabalho camponês. Os espaços do Entre Ribeiros, sendo reocupados pelo capital e por campesinos, transformaram-se em propriedades capitalistas e propriedades camponesas.

Para Fernandes (2008), "as propriedades camponesas e as capitalistas são territórios distintos, são totalidades diferenciadas, que produzem relações sociais diferentes, que promovem modelos divergentes de desenvolvimento". Apesar de distintos quanto aos conteúdos e finalidades, estes territórios, a partir de seus sujeitos sociais, o colono/capitalista/rentista e o assentado, demonstram algumas tímidas relações de complementariedade entre si, para não corrermos o risco de falarmos em uma "solidariedade" entre aqueles que são postos como desiguais.

Apesar disso, a relação entre sujeitos sociais diferentes ocorre no lugar. São conexões estabelecidas espontaneamente entre os dois lados, parecendo crer que nenhum deles está sendo desfavorecido. Ela se dá no sentido de que, ao necessitar de mão-de-obra, temporária ou permanente, ela é encontrada no assentamento como que na forma de reserva, o que implica obter mão-de-obra barata 
e disponível nos momentos de plantio e de colheita. Por outro lado, estes se submetem a tal situação em função de terem acesso a diversos subprodutos da atividade produtiva do agronegócio local.

O feno, por exemplo, quando não atende às exigências do mercado devido à baixa qualidade, é vendido a preços "irrisórios", sendo desta forma acessível aos assentados, ficando pago em algumas ocasiões com o próprio trabalho. De forma análoga a palha de feijão é colhida pelo assentado utilizando maquinários dos produtores, de modo que o resultado do trabalho do primeiro é dividido com o segundo. No caso da colheita das abóboras, o "refugo" ou o "restolho", ou seja, o que o mercado não absorve, é descartado ainda na lavoura. Para o empresário, o refugo não significa mais que matéria orgânica para o solo, com o qual não é muito preocupado, diante do acesso ao crédito para compra de fertilizantes. Se a doação é vista pelos colonos como limpeza da terra, para os assentados é alimento abundante para seu rebanho. O subproduto que já remunerou devidamente o colono transforma-se em recurso para subsidiar a manutenção do rebanho, coincidentemente, no período da estiagem.

\section{CONSIDERAÇÕES FINAIS}

O que fica desse estudo são as tensões territoriais. Nelas observamos coexistências e/ou tolerâncias de diferentes temporalidades e lógicas sociais. Complexas e assimétricas são também as relações sociais. Contudo, aparentemente, os processos de exploração do trabalho se confundem com ações de complementaridade ou solidariedade entre aqueles que são desiguais.

Nesta relação, não há contrato, mas permissão pactuada entre as partes, um acordo tácito permitindo que haja maior obtenção de renda da terra e do trabalho alheio por parte do proprietário, sem que este tenha que remunerar o trabalho vivo.

Percebe-se nesta relação processos antigos de exploração do trabalho. Estão envolvidas formas não capitalistas de produção que são acionadas para a reprodução do capital investido no campo, conforme aponta Martins (1981).

Assim, a relação de subordinação e/ou exploração dos Assentados não está relacionada somente ao agronegócio do Entre Ribeiros onde ele negocia seu tempo em troca de salários ou subprodutos, mas também da Cooperativa onde ele se abastece e para a qual "entrega" o leite. Destarte, em todas as instâncias ele vê o seu trabalho sendo apropriado pelo grande capital, quando não é pelo agronegócio praticado nos lotes dos colonos do Entre Ribeiros, onde vendem sua capacidade de trabalho, é pela cooperativa para a qual vendem leite. Vivem, assim, situações muito próximas à interpretação de Wanderley (2001), pois em geral são "trabalhadores para o capital", ao se tornarem assalariados permanentes ou temporários na usina de cana ou nas lavouras de grãos, além de produzirem leite e frutas em suas parcelas de terras.

Ainda em busca da construção de sua própria identidade em um território "satélite" dos territórios tornados arena do capital, os camponeses se veem ora proprietários, ora trabalhadores assalariados. O assalariamento ainda é uma realidade entre os assentados, mas é ao mesmo tempo, uma etapa que esperam vencer, para afirmar-se cada vez mais como camponeses.

Entre Ribeiros é para nós o quadro síntese, grosso modo, do que é o campo no Brasil. Um quadro decorrente das políticas públicas centralizadas no agronegócio que se desenvolve em espaços tecnificados, mecanizados, com elevados investimentos de capital, acesso ao crédito, tecnologia, trabalho assalariado e alta produtividade. Quanto ao campesinato, os territórios são poucos tecnificados, com insuficientes subsídios do Estado, limitado acesso ao crédito e à tecnologia, baixa produtividade e predomínio do trabalho familiar, fazendo a agricultura camponesa andar a passos lentos.

A agricultura desenvolvida nos Cerrados do Entre Ribeiros pelos colonos/capitalistas/rentistas e assentados nos revelam a ação do Estado, o ator sintagmático no processo de construção dos territórios e seus projetos políticos para o campo, diferenciados e direcionados aos colonos e aos assentados; ações que produzem resultados distintos para os sujeitos vindos de fora do lugar.

Assim, para os colonos, a reterritorialização foi associada aos privilégios concedidos pelas políticas públicas oficiais; já para os assentados a reterritorialização envolveu a organização política coletiva na busca pelo retorno à terra, e esta, depois de conquistada na forma de assentamento, o desafio de torná-lo lugar de reprodução da vida. 


\section{REFERÊNCIAS}

CARVALHO, H. M. O campesinato no século XXI: possibilidades e condicionantes do desenvolvimento do campesinato no Brasil. Petrópolis-RJ: Vozes, 2005.

FERNANDES. B. M. Entrando nos territórios do território. In: PAULINO, E. T., FABRINI, J. E. (Orgs). Campesinato e territórios em disputa. São Paulo: Expressão Popular, 2008

HAESBAERT, R. O mito da desterritorialização: do Fim dos Territórios à multiterritorialidade. Rio de Janeiro: Bertrand Brasil, 2004.

HEIDRICH, A. L. Território, integração socioespacial, região, fragmentação e exclusão social. In: RIBAS, A. D.; SPÓSITO, E. S.; SAQUET, M. A (orgs). Território e desenvolvimento: diferentes abordagens. Francisco Beltrão: UNIOESTE, 2004. P. 37-66.

IBGE - Instituto Brasileiro de Geografia e Estatística. Shape Brasil, 2007.

INCRA - Instituto Nacional de Colonização e Reforma Agrária. Planos de Assentamento, 2018.

KINN. M. G. Lugares e territórios camponeses em iniciativas turísticas: os usos do espaço no entorno dos lagos das Hidrelétricas Amador Aguiar I e II - Triângulo Mineiro - MG. 2010. Tese (Doutorado em Geografia) - Programa de Pós-Graduação em Geografia da Universidade de São Paulo, São Paulo, 2010

LOURENÇO. L. A. B. A Oeste das Minas: escravos, índios e homens livres numa fronteira oitocentista, Triângulo Mineiro (1750-1861). Uberlândia: EDUFU, 2005.

MARCOS, V. Agricultura e mercado: impasses e perspectivas para o agronegócio e a produção camponesa no campo latino-americano. In: PAULINO, E. T., FABRINI, J. E. (Org.). Campesinato e territórios em disputa. São Paulo: Expressão Popular, 2008.

MARTINS. J de. S. Os camponeses e a política no Brasil. As lutas sociais no campo e o seu lugar no processo político. Rio de janeiro: Editora Vozes, 1981.

MATOS, P. F. As tramas do agronegócio nas "terras" do Sudeste Goiano. 2011. Tese (Doutorado em Geografia) - Programa de Pós-Graduação em Geografia. Universidade Federal de Uberlândia, Uberlândia, 2011. 355 p.

MIRANDA NETO, M. J. Os lucros da fome: o mito da escassez de alimentos. Rio de Janeiro: Achiamé, 1982.

OLIVEIRA, A. U. A Geografia das lutas no campo. São Paulo: Contexto, 1996.

OLIVEIRA, A. U. Campesinato e agronegócio: uso da terra, movimentos sociais e transformações no campo. In: FEITOSA, A. M. A.; ZUBA, J. A. G.; CLEPS JUNIOR, J. Debaixo da lona: tendências e desafios regionais da luta pela terra e da reforma agrária no Brasil. Goiânia: Editora da UCG, 2006.

OLIVEIRA MELLO, A. de. As Minas reveladas: Paracatu no tempo. Paracatu: Editora da Prefeitura Municipal de Paracatu/MG, 2002.

PESSÔA, V. L. S. Ação do Estado e as transformações agrárias no Cerrado das zonas de Paracatu e alto Paranaíba-MG. Tese de Doutorado. Rio Claro, 1988.

RAFFESTIN, C. Por uma geografia do poder. São Paulo: Ática, 1993.

RICCI DOS SANTOS, R. Crise hídrica na irrigação: o caso do Ribeirão Entre Ribeiros/MG. Brasília: Universidade de Brasília, 2007.

SAN MARTIN, P; PELEGRINI, B. Cerrados: uma ocupação japonesa no campo. Rio de Janeiro: Codecri, 1984.

SANTOS, R. J. Gaúchos e Mineiros do Cerrado: metamorphoses das diferentes temporalidades e lógicas sociais. Uberlândia: EDUFU, 2008.

SAQUET, M. A. Abordagens e concepções de território. São Paulo: Ed. Expressão Popular, 2007.

SILVA, J. F. G da. A modernização dolorosa: estrutura agrária, fronteira agrícola e trabalhadores rurais no Brasil. Rio de Janeiro: Zahar, 1982. 
SILVA, P. S. M. Benditos Amaros - Remanescentes quilombolas de Paracatu: memórias, lutas e práticas culturais. Tese (Doutorado em História) - Programa de Pós-Graduação em História. Uberlândia, Universidade Federal de Uberlândia, Uberlândia, 2012.

SOUZA, A. G. A territorialização do agronegócio canavieiro em Frutal-MG. Dissertação (Mestrado em Geografia) Programa de Pós-Graduação em Geografia, Universidade Federal de Uberlândia, Uberlândia, 2012. $186 p$

WANDERLEY. M. N. B. Raízes históricas do campesinato Brasileiro. In: TEDESCO. J. C. Agricultura familiar: realidades e perspectivas. Passo Fundo: UPF, 2001.

Recebido em: 10/10/2017

Aceito para publicação em: 09/05/2018 